\title{
AS RUAS CONTRA O NEOLIBERALISMO? MANIFESTAÇÕES EM 2019 NA AMÉRICA LATINA, FOCO NO CHILE
}

\author{
Fernando José Martins iD) 1
}

Resumo: Em torno do conceito de movimento antissistêmico, figuram distintas categorizações sobre os movimentos sociais. Iniciando com considerações conceituais, o artigo localiza, no ano de 2019, uma série de manifestações nas ruas da América Latina. Faz considerações mais específicas sobre o caso chileno, com a exposição de fotografia das ruas de Santiago e Valparaiso. As análises evidenciam elementos similares no conjunto das manifestações, apresentando como característica comum a rejeição do modelo neoliberal hegemônico na região.

Palavras-chave: Movimentos Sociais; mobilizações; neoliberalismo.

\section{THE STREETS AGAINST NEOLIBERALISM? MANIFESTATIONS IN 2019 IN LATIN AMERICA: FOCUS ON CHILE}

Abstract: Around the concept of anti-systemic movement, there are different categorizations about social movements. Starting with conceptual considerations, the article finds, in 2019, a series of demonstrations on the streets of Latin America. It makes more specific considerations about the Chilean case, with an exhibition of photography of the streets of Santiago and Valparaiso. The analyzes show similar elements in the set of manifestations, presenting as a common characteristic the rejection of the hegemonic neoliberal model in the region.

Keywords: Social movements; mobilizations; neoliberalism.

\section{Introdução}

O posicionamento dos movimentos sociais contra o modo de produção hegemônico é uma pauta recorrente na história em diferentes períodos. Desde os "rebeldes primitivos" (Hobsbawm, 1970) ou até mesmo antes deles, passando por revoltas, insurgências republicanas, movimentos de libertação, de classes operárias até chegar às contestações que conhecemos atualmente. Dado a multidimensionalidade que os movimentos apresentam na atualidade, mais intensamente após a consolidação dos chamados novos movimentos sociais, questiona-se a dimensão contestatória da totalidade de tais movimentos. Porém, mesmo com pautas específicas, muitos movimentos sociais, protestos de rua, manifestações de massa, mantém a perspectiva integral das reivindicações em busca de uma transformação estrutural nas relações sociais.

${ }^{1}$ Doutor em Educação pela Universidade Federal do Rio Grande do Sul (UFRGS). Professor do colegiado de pedagogia, do Centro de Educação, Letras e Saúde da Universidade Estadual do Oeste do Paraná (Unioeste), Foz do Iguaçu. E-mail: fernandopedagogia2000@yahoo.com.br. 
No bojo da ação desses novos movimentos sociais, encontram-se aqueles que se pautam em uma demanda específica ou até mesmo pontual, mas articulam suas demandas com uma ampla contestação da organização societal. E conta-se ainda com os movimentos que são em si uma ação contra o modelo de organização vigente, os quais, em uma ampla conceituação, podem ser chamados de "antissistêmicos". Em si, a categorização de tais movimentos já é parte integrante dos objetivos a serem alcançados no presente artigo, pois, em seu rol encontra-se uma certa diversidade.

Embora concisa, é elucidativa a afirmação de (ARRIGHI, HOPKINS, WALLERSTEIN 1989, p.1) na introdução de seu livro: "O sistema aqui referido é o histórico sistema-mundo do capitalismo que, como argumentamos, deu origem a um conjunto de movimentos antissistêmicos." Esse conjunto pode ser definido como: movimentos altermundistas ou antimundialização, antiglobalização, anticapitalismo ou antineoliberais, conceitos que são brevemente conceituados no desenvolvimento do texto.

A característica a ser destacada na análise é o caráter antineoliberal das manifestações de rua. O olhar estará voltado para a realidade latino-americana, com maior ênfase nas ruas chilenas. As experiências neoliberais em todo o sistema-mundo do capital têm, na américa latina, uma relação experimental contundente, "Vale dizer que a primeira experiência de neoliberalização ocorreu no Chile, depois do golpe de Pinochet, no "pequeno 11 de setembro" (...) (HARVEY, 2008, p.18) e, depois disso, em suas várias metamorfoses. Foi nesse espaço que as populações sofreram e sofrem "na pele" as consequências sociais das políticas e práticas neoliberais, capitaneadas pelo Estado, com oscilações de intensidade, mas com grande impacto em todo continente.

Tais impactos agravam a precariedade da população e geram independentemente do nível de organização, consciência de classe ou participação em movimentos sociais - um elevado nível de descontentamento e revolta na população em geral. A partir daí, facilitado pela massificação de instrumentos de comunicação social, temos observado grandes mobilizações que questionam políticas (ou falta delas), governos, condições de vida entre outras demandas.

Aqui reside uma necessária intervenção, também conceitual, que é crucial para análises: a distinção entre protestos, atos públicos e manifestações da própria categoria movimentos sociais. Muitos dos chamados movimentos antissistêmicos podem se restringir somente a ações de rua e não alcançar a totalidade da terminologia e, consequentemente, a se realizar na práxis de um movimento social.

De modo geral, faz-se necessário, antes de abordar a onda de movimentos sociais e sua luta contra o neoliberalismo nos tempos mais recentes, perceber a trajetória, tanto prática quanto conceitual dessa tipologia de movimentos sociais. E ainda, para entendimento do movimento atual, perceber também o "flerte" que as ruas apresentaram com movimentos de direita, conservadores e de contrarresistência, como ocorre há tempos na Venezuela, no Brasil pós-2013 e em outras manifestações.

\section{Referencial teórico}




\subsection{As bases antissistêmicas}

Este conceito é chave para a compreensão analítica dos atos que observamos em particular. Porém, como é recorrente no debate acadêmico, trata-se de um conceito complexo e com diversas interpretações e, de todo modo, sujeito a críticas. Sinalizando essa multiplicidade, encontram-se posicionamentos que mantêm uma coerência epistemológica efetiva, seja ancorando-se em categorias marxianas construindo dialeticamente as aproximações com conceitos clássicos, seja na construção de categorias analíticas novas, porém sustentadas em paradigmas clássicos. Porém, de outro lado, correntes ligadas ao movimento intelectual pós-moderno, inserem no "sistema" a ser combatido, também concepções paradigmáticas clássicas, o que culmina com práticas sociais tão diversificadas, nas quais cabem também posicionamos e ações que defendem a reprodução do sistema vigente. Casos concretos podem ser identificados nas ruas do Brasil, ocupadas desde 2013, por manifestações diversas, muitas delas de caráter reacionário, que alimentam e potencializam as bases de reprodução do capital no cotidiano.

Realizaremos aqui apontamentos que visam a problematizar historicamente o conceito, mas também delimitar conceitualmente elementos que julgamos serem cruciais para a compreensão dos movimentos antissistêmicos. Assim, ao resgatar a reivindicação de Immanuel Wallerstein sobre o termo, localizamos a gênese e a forma do debate:

Cunhei o termo de 'movimento antissistêmico' nos anos 70 porque queria encontrar um vocábulo que pudesse abarcar o que histórica e analiticamente haviam sido dois tipos diferentes de movimentos populares, marcadamente distintos e rivais em muitos aspectos: os chamados movimentos sociais e os movimentos nacionais. (WALLERSTEIN, 2005, p. 263).

Nessa afirmação, Wallerstein reivindica a autoria da sistematização da expressão que se tornou categoria de análise para os movimentos sociais e também localiza temporalmente o feito. Fato expressivo para compreensão do contexto histórico. Na mesma obra, o autor indica um momento marcado por uma contradição fundamental, pois ao detalhar os dois "tipos diferentes de movimentos populares" ele constata que ambos, evidenciam uma determinada hegemonia de um campo "progressista" nos estados nacionais, seja pela onda social-democrata ou mesmo do conjunto dos países liderados pelo socialismo real, ou seja, por força de libertação que tornam independentes colônias tardias e outros formatos de dominação, o que ele chama de movimentos nacionais. Porém, ao mesmo tempo, indica-se, pelo movimento popular, um esgotamento de capacidade civilizatória do sistema mundo, centrado na dominação sistêmica.

Assim, o autor elege como marco histórico as mobilizações mundiais de 1968, que expressam a lógica do movimento antissistêmico, além de materializarem ações e práticas. Ocorre que a contestação contida em tais movimentações extrapola o campo da dominação econômica, expondo com notoriedade movimentos ligados às pautas identitárias, o que faz dilatar a compreensão sobre o "sistema" que é contestado. Também são alvo das 
contestações as indicações de coexistência de práticas nas quais se busca a extinção das classes sociais, mantendo-se a organização patriarcal, preconceituosa. Vale ressaltar que tais indicativos são apontados pelo autor, mas não assumidos como cerne de suas reflexões, pois "(...) para Wallerstein (2003), a aposta está nas lutas de classes. O autor propõe uma mudança para acabar com a relação de exploração, quebrando com os ciclos interligados e sucessivos, próprios do capitalismo" (CARVALHO, 2008, p. 222).

Ainda que a perspectiva de Wallerstein possa ser considerada pioneira e fundamental em tais estudos, as abordagens não se circunscrevem nessa perspectiva. Ao sistematizar criticamente os movimentos antissistêmicos, Giane Alves de Carvalho (2008) concentra a ressignificação de movimentos de tais natureza, em duas visões: a que já fora exposta, a partir de Wallerstein "e uma visão de um estilo habermasiano quando se situam os movimentos sociais num constante diálogo entre esfera pública e privada" (CARVALHO, 2008, p. 222). Tais visões se expressam na prática dos movimentos sociais, os quais buscam materializar suas demandas de forma pragmática e material, que podem ser efetivadas também como políticas públicas. Essas ações se realizam em uma fronteira tênue, que pode se aproximar de processos que a análise gramsciana chamaria de "revolução passiva" ou, como diz diretamente Pablo Gonzales (CASANOVA, 2001-2002, p.28), falando diretamente sobre o tema em tela: "Como sempre, alguns grupos anti-sistêmicos reproduzirão parte das estruturas sistêmicas de dominação e acumulação".

Em que pesem as manifestações, movimentos e, principalmente, as organizações não-governamentais que podem flertar com ações de reprodução do sistema, mesmo com "bandeiras antissistêmicas", é necessário abordar também movimentos sociais, de causas específicas, às vezes locais, que mantêm e alimentam toda a perspectiva antissistêmica, desde os Zapatistas no México ou o MST no Brasil que, por suas vezes, criam redes que são, em si, movimentos, como é o caso da Via Campesina. Tais exemplos podem ser encontrados ligados aos debates dos novos movimentos sociais, feministas, de gênero, raça, ambientais entre outros. Movimentos que mantêm, não só em perspectiva, mas em suas práticas, dimensões antissistêmicas essenciais.

A década atual é marcada por uma ampla utilização das ruas como espaço de protestos, inclusive, autores, como Raul Zibechi, fazem uma importante reflexão sobre a territorialização desses espaços. Reafirmado na análise de (GOHN, 2019, p. 17): "As ruas se transformaram em territórios de cidadania $(\ldots)^{\prime \prime}$, porém essas ruas não são tomadas somente por sujeitos que visam à transformação, como indica a continuidade da afirmação "(...), mas também houve espaço para a criação de organizações movimentalistas liberais ou conservadoras (...), o que nos leva a retomar um importante debate, sobre a diferenciação entre movimentos sociais e mobilizações e protesto". Para se vincular ao debate aqui proposto, vamos reproduzir a análise de (ROJAS, 2013, p. 7), em seu artigo que, sugestivamente, questiona o que são movimentos antissistêmicos:

Mobilização social pode ser de grandes dimensões, porém, se distingue claramente de um verdadeiro movimento social, que é algo mais permanente, organizado, que trabalha de maneira constante e planejada, 


\begin{abstract}
e que delineia explicitamente objetivos não somente imediatos, mas também de médio e, até mesmo, de longo prazo. É claro que um movimento social pode gestar-se em sua origem a partir de uma mobilização social, ou também, um movimento social já consolidado pode em certa conjuntura política convocar diversas mobilizações sociais pontuais e concretas, no entanto, é preciso ter consciência de que se trata de duas expressões distintas de uma mesma e subjacente inconformidade social das classes e setores subalternos da sociedade.
\end{abstract}

Ao refletir sobre as distinções entre mobilização e movimento social, Rojas ressalta a inconformidade social. Ocorre que, nos tempos atuais, as sinalizações advindas das ruas são, por vezes, ambíguas, como já afirmamos, expondo uma face conservadora e liberal que se distingue da essência do movimento antissistêmico. O que nos leva a compreender um último aspecto conceitual importante: de que sistema estamos falando?

A continuidade da análise de (ROJAS, 2013, p.9) indica que "essas lutas ou movimentos são identicamente anticapitalistas e antissistêmicos". O próprio Wallestein, na obra "mater" do debate aqui proposto: Arrighi, Hopkins e Warllestein (1989) indicam o sistema-mundo como o sistema capitalista. Assim, a perspectiva que se toma é que o referido sistema é o capitalista, perspectiva que também é hegemônica no debate sobre os movimentos antissistêmicos. Contudo, a partir da inserção dos novos e novíssimos movimentos sociais, há uma tendência de ampliação do conceito de sistema, ou seja, sistemas no plural, de opressão de outras naturezas, identitárias, políticas e até mesmo sociais, que não se debruçam sobre o questionamento da dinâmica do capital.

Assim, em nosso entendimento, ainda que existam, entre os movimentos sociais, concepções distintas de sistema (social, político, identitário), a compreensão dos movimentos antissistêmicos é uma compreensão anticapitalista. E essa afirmação advém da prática do método utilizado no presente artigo. Ainda que polêmica, compartilha-se da premissa marxiana de que, em última instância, impõe-se a determinação econômica na lógica da reprodução capitalista. Em síntese, durante a hegemonia do sistema capitalista, os movimentos antissistêmicos, ainda com suas particularidades, são movimentos anticapitalistas.

\title{
2.2 Altermundistas, Antiglobalização e variáveis
}

Derivado do contexto já apresentado, podemos ainda categorizar tais demandas, seguindo a mesma essência de ação, movimentos chamados altermundistas, antiglobalização, ou variáveis como anti-mundialização ou ainda, por um outro mundo possível. São conceitos ainda mais aproximados, mas sempre com determinadas especificidades, que são descritas em diferentes estudos acadêmicos, como teses, dissertações e artigos aqui relacionados. Vale novamente ressaltar o caráter anticapitalista de tais ações e uma característica perene - que conduz a análise contida neste artigo - que localiza no formato neoliberal a gênese e a essência desses movimentos, distintos e similares.

Boa parte dos estudos, inclusive os que estão aqui relacionados, tem um ponto em comum ao se manifestar historicamente sobre o emblemático ponto 
de partida para tais movimentos, conforme é expresso no texto de José Seoane e Emilio Taddei:

A gênese do movimento antimundialização parece conduzir às profundezas da selva chiapaneca em meados de 1996. Numerosos cronistas insistiram em assistir o Primeiro Encontro Intercontinental pela humanidade e Contra o Neoliberalismo (realizado de 27 de julho a 3 de agosto de 1996) como o primeiro elo do movimento internacional contra a mundialização liberal. (SEOANE; TADDEI, 2001, p. 153-154).

Essa referência sintetiza vários aspectos encontrados na literatura sobre o tema, inicialmente, a localização de sua gênese no interior do movimento zapatista mexicano e, de modo indireto, o reconhecimento de tal movimento para a compreensão da articulação além das fronteiras e do protagonismo de movimentos locais no processo das lutas mundiais, internacionais e transnacionais. Da mesma forma, o avanço orgânico do capital sobre esses sujeitos. O texto localiza temporalmente o marco mais emblemático e citado para a origem dos movimentos de tal natureza, ainda no século XX. Mesmo que o nome do encontro possa divergir em algumas fontes, a ideia de luta internacional contra o neoliberalismo, especificamente, traduz a essência da atividade que é sinalizada como fonte histórica primordial.

Para as finalidades do presente artigo, vamos concentrar as conceituações em duas nomenclaturas: movimentos antiglobalização e altermundistas. Ressalta-se que há mais terminologias para fenômenos dessa natureza e também que muitos estudiosos compreendem as duas definições como partes de um mesmo movimento social, porém localizamos especificidades entre os estágios de tais movimentos e papeis, às vezes, distintos no processo de organização social.

Os movimentos antiglobalização têm uma marca bastante distinta de se constituírem como reação aos organismos e ações que representam a organização do capital financeiro, portanto, a centralidade do sistema capitalista e sua capilaridade global. De modo geral, as ruas são as paisagens mais comuns da ação de tais movimentos e não são ruas aleatórias. Seattle, Genova, Davos, Londres, Praga, entre outras cidades do mundo, abrigaram rodadas dos organismos multilaterais, cúpulas, reuniões estratégicas, fóruns ligados às organizações do capital e, consequentemente, os movimentos de resistência que conceituamos neste texto.

Fizemos a opção de não fazer referência aos movimentos específicos e aos organismos contestados, pois entendemos que 0 chamado movimento antiglobalização é muito mais plural e capilarizado que os registros das experiências. $\mathrm{E}$, assim, $\mathrm{o}$ indicativo de algumas experiências emblemáticas pode invisibilizar outras ações que cumprem a mesma função social. Nesse sentido, endossamos a conceituação exposta por Breno Bringel e Enara Echart Muñoz que dão ênfase às identidades coletivas que compõem e constroem o movimento:

Entendemos o movimento antiglobalização, num sentido amplo, como um movimento social global que aglutina redes e movimentos sociais diversos (ambientalistas, feministas, sindicais, de defesa dos direitos humanos, 
entre outros) para além de suas diferenças, com uma perspectiva que une o local e o global, construindo identidades coletivas multirreferenciais que superam o Estado-nação e uma luta comum contra a globalização neoliberal, a quem responsabilizam as múltiplas problemáticas contra as que se mobilizam (BRINGEL; MUÑOZ, 2010, p. 29).

Essa densidade de sujeitos sociais coletivos e organizados, cuja ação culmina em verdadeiras "batalhas" nas ruas, em manifestações contra organizações que representam o grande capital e a globalização, tem uma tessitura de comunicação e agitação que é crucial para o êxito das ações desenvolvidas. É fato que a rede de comunicação fora deveras ampliada com a utilização dos recursos digitais, que proporcionam, inclusive, a adesão do cidadão comum, aquele que não está inserido na rede de movimentos sociais já consolidados que dão suporte ao movimento antiglobalização em ação.

Até chegar às ruas ou depois das ações públicas, esse movimento vai criando mecanismos de organização que também podem ser chamados de antiglobalização, porém, essa estrutura organizada, visando a congregar formalmente as ações para a superação da lógica globalizante do capital, pode ser chamada de movimento altermundista. Talvez seja esse justamente o diferencial mais efetivo entre tais práticas: a construção de espaços materiais, em plenárias, encontros, fóruns, conferências, assembleias, identifica uma diferença mais clara entre esses dois movimentos. Mas é necessário ressaltar efetivamente que são ações simbióticas, que se constroem e se reconstroem mutualmente e são indissociáveis.

Um indicativo efetivo de tal proximidade reside justamente nas conceituações acadêmicas que são encontradas nas diferentes obras sobre os movimentos. Na sequência, faremos a transcrição da síntese de Michael Lowy, agora sobre o movimento altermundista:

O movimento altermundialista é sem dúvida o fenômeno mais importante de resistência anti-sistêmica do início do século XX. Esta vasta nebulosa, esta espécie de "movimento dos movimentos", que se manifesta de forma visível por ocasião dos Fóruns Sociais - regionais ou mundiais - e das grandes manifestações de protesto - contra a OMC, o G8 ou a guerra no Iraque - não corresponde às formas habituais da ação social ou política. Grande rede descentralizada, é múltipla, diversa e heterogênea, associando sindicatos operários e movimentos camponeses, ONGs e organizações indígenas, movimentos de mulheres e associações ecológicas, intelectuais e jovens ativistas (LÖWY, 2008, p. 32).

A indicação conceitual acima evidencia novamente as aproximações e, também, como já indicamos, aponta, com maior ênfase, aos espaços dos fóruns organizacionais. Entre eles, vale fazer uma alusão ao caráter emblemático ao Fórum Social Mundial, com origens brasileiras na cidade de Porto Alegre, com variações itinerantes pelo mundo. Não vamos fazer um debate sobre a organização e alcance dessa atividade, pois muitos trabalhos acadêmicos já foram desenvolvidos sobre ela Giovanni (2013) e Santos (2005). O que é possível ressaltar nesse exemplo é a agenda comum de conteúdo programático de consenso entre tão distintos movimentos, agências e organizações que 
compuseram a atividade. Ações e práticas que se materializam novamente, direta ou indiretamente, nas ruas.

Esses vínculos entre ruas e eventos evidenciam fronteiras tênues entre os conceitos. Porém não há dúvidas de que tratamos de movimentos sociais de contestação à globalização neoliberal. Contudo, antes de avançar, é importante ressaltar duas questões de contraposição: primeiro, como o próprio artigo utilizado para destacar o conceito de movimento antiglobalização evidencia em um de seus subtítulos, os: "Sinais de esgotamento e desdobramentos: crise do movimento e crise conceitual" (BRINGEL; MUÑOZ, 2010, p. 33). Há, no próprio movimento, um declínio de ação, que não indica necessariamente enfraquecimento, mas sim, de descentralização e reconstrução. A segunda questão a ser levantada é justamente o posicionamento crítico acerca de tais movimentos. Pesquisas mostram a ausência do caráter de classe trabalhadora em tais ações Arias (2003), ou ainda equívocos na dinâmica das ações Ferreira (2002), e também, no contexto geral, há críticas ao caráter polissêmico e liberal das proposições efetuadas, ou ainda, a ênfase em um "outro mundo possível", omitir a perspectiva socialista da ação antissistêmica.

As observações que finalizam a reflexão sobre os movimentos abordados não têm objetivo de minimizar suas ações. Somente busca evidenciar o movimento contraditório na compreensão de tais fenômenos. Porém, todas as abordagens indicam que, notoriamente, há uma movimentação que ganha as ruas e contesta a hegemonia da organização neoliberal globalizante.

\subsection{As ruas da América Latina, como andam?}

O desenvolvimento deste artigo vai se aprofundar em elementos dos protestos e marcas das ruas de um país latino-americano: o Chile. Porém, compreendemos que as aproximações das realidades dos países latinoamericanos nos permitem realizar análises que olhem para a "pátria grande". $\mathrm{E}$ assim, antes de adentrar no caso específico, vamos localizar em diversos países, protestos realizados no ano de 2019, evidenciando similitudes e resistências.

Os protestos de rua não são fenômenos fáceis de serem sistematizados ou registrados. É possível que todos os países da região latino-americana tenham sido cenário dessas ações e, mesmo as que serão aqui relatadas, podem deixar de fora condicionantes importantes, porém, ainda assim, a menção de tais protestos são necessárias para a identificação de um fenômeno, que não é isolado e, em certa medida, dialoga com os movimentos já arrolados no desenvolvimento do texto. E cabe aqui também uma observação metodológica: dada a data recente, ainda não encontramos significativos registros acadêmicos sobre toda a extensão das ações citadas. Assim, iremos narrar os fatos de acordo com relatos publicados em meios de comunicação de massa, a partir do abrangente aglomerado de informações Visentainer (2020) e também a Revista de Ciência Política de Santigo no Chile, em número dois do volume 40, que versa sobre as manifestações de 2019 e, ainda, nos casos pormenorizados, preferencialmente completados com fontes do país de origem dos fatos.

As reformas de Estado estão entre as normativas essenciais do receituário neoliberal. Assim, os governos, ainda que tendidos à social-democracia, que 
promovem tais reformas, mesmo sem admitir, obedecem a tais prescrições. É o caso da reforma constitucional do Panamá. Zamorano (2019). Além da estrutura estatal, as mudanças pretendidas também tocaram questões de gênero, com mudanças no ordenamento LGBT e as manifestações geraram prisões. Ainda na América Central, vale citar os protestos que se deram a partir da reforma da previdência de Daniel Ortega na Nicarágua Buben; Kouba (2020); contra privatizações em áreas essenciais, como saúde e educação em Honduras Rodríguez; Tule (2020); mortes e protestos na crise do Haiti (Parra, 2020); protestos contra as medidas de Estado de sítio na Guatemala.

Também o México, nosso "Hermano" que se localiza na América do Norte, foi campo de duros protestos em 2019. Ainda que localizado no âmbito de centro-esquerda e promovendo aumentos no salário-mínimo, o governo de Andrés Manuel López Obrador enfrenta uma forte reação popular, com uma onda de protestos em seu primeiro ano de presidência. O centro da insatisfação popular é a questão da segurança, violência e outras mazelas do sistema, que são resultados da prática concentradora intensificada pelo modelo neoliberal. É isso que relata o veículo que retrata o cotidiano mexicano INFOBAE, documentando com imagens os protestos de 2019 e também vale ressaltar o registro acadêmico que contextualiza as manifestações de Talanquer (2020). Soma-se a tal situação a emblemática organização das mulheres, que repudiaram de forma veemente a violência contra a mulher, a cultura do estupro. Essas manifestações já contam com publicações acadêmicas Cerva Cerna (2020) e Esquivel Domínguez (2019) que narram o fenômeno, sua abrangência e a ênfase na articulação digital e a participação em redes sociais dos mesmos.

No espaço sul-americano, também houve intensas manifestações. Para fins de delimitação, aqui, como o foco serão às ruas chilenas, iremos apresentar o caso da Colômbia com mais informações e passar pela contradição das terras brasileiras antes de adentrar ao Chile.

A escolha das manifestações pelas ruas colombianas não foi aleatória. Trata-se de um movimento muito aproximado de uma unificação de vários segmentos sociais: os indígenas, LGBTs, camponeses, estudantes e que culmina com uma grande greve nacional, envolvendo então a classe trabalhadora como um todo. Como em todos os outros casos nacionais narrados, há variantes de problemas locais. Os problemas das drogas, ações bilaterais com a Venezuela, o processo de paz e ações relacionadas às FARCs (Forças Armadas Revolucionárias da Colômbia) estão entre as causas da efervescência social Abitbol (2021). A síntese da motivação das ruas é "(...) social unrest caused by multiple and widespread frustration about public education, health, corruption, governance, and the environment (...)" (RETTBERG, 2020, p. 235). O meio de comunicação colombiano "El Espectador" narra os protestos sociais até a greve nacional com a voz dos envolvidos em um formato de documentário. Ele traz as informações referentes à participação de distintos sujeitos coletivos, juventude e estudantes. Esses últimos tiveram um envolvimento que fortaleceu novamente o movimento estudantil Borda (2020).

Em síntese, a greve nacional ou, como fica melhor na língua nativa "el paro nacional" não é essencialmente um movimento grevista. É o conjunto das 
mobilizações de vários seguimentos da sociedade. De modo imediato, as reações eram contra as reformas tributária, previdenciária, trabalhista, proposta pelo governo Iván Duque. Porém, como alguns setores denominaram, era reação ao "paquetazo neoliberal" (Aguilar-Forero, 2020) que dialoga com nosso tema central. É importante salientar que eventos da mesma natureza, com as variações locais, aconteceram na maioria dos países da região: Paraguai, Argentina, Equador, Venezuela, Peru, Uruguai, Bolívia e nas Guianas e Suriname, além dos casos pormenorizados.

O caso brasileiro tem uma faceta interessante, que se reproduziu também em outros países: a forte presença das forças de direita nas ruas. Sem ainda uma sistematização acadêmica (as manifestações antecedentes, a partir de 2016 são prioritárias), existem dois principais focos de manifestações no Brasil em 2019. De um lado, houve uma intensa mobilização em defesa da educação e da ciência e tecnologia, principalmente por estudantes e professores e contra o corte de verbas das instituições públicas brasileiras. As manifestações ocorreram em mais de duzentas cidades de todo país, com maior intensidade nas capitais. O fato obteve cobertura da mídia e uma reação negativa por parte do governo brasileiro. De outro lado, o campo mais conservador também se organizou e saiu às ruas. Os atos foram de apoio ao governo e ao presidente Jair Bolsonaro e contra outros poderes da república: o judiciário, centrado no supremo tribunal federal e contra o legislativo. Essa realidade contraditória evidenciou que, novamente, as ruas foram protagonistas do processo.

\section{Metodologia}

Metodologicamente, o conteúdo do presente texto é resultado de uma combinação de estratégias de pesquisa: inicialmente composto de uma revisão bibliográfica para o desenvolvimento de um quadro conceitual, desde a essência dos movimentos antissistêmicos, até suas "derivações" ou oscilações com conceitos adjuntos: movimentos antiglobalização, altermundista e, finalmente, nosso foco mais delimitado, os movimentos antineoliberais. Essa revisão de literatura atinge ainda experiências práticas, ou seja, movimentos efetivos que são contidos sob as terminologias abordadas - tanto os movimentos amplos oriundos da temática antissistêmica propriamente dita (como o Fórum Social Mundial, Occuppy, Indignados, Seatle, Genova e similares) como movimentos que atuam em demandas específicas, mas contém ações antissistêmicas (como os Zapatistas, MST e outros movimentos de demandas mais particulares). É importante frisar que tais referências são integrantes da análise, mas não são foco do presente artigo, ou seja, não haverá um detalhamento ou aprofundamento em tais experiências.

Alcançaremos, nesta análise, ações nas ruas latino-americanas do ano de 2019, de acordo com notícias veiculadas pela mídia alternativa (blogs, páginas) e, na medida do possível, a imprensa "oficial". Porém, muitas reflexões serão feitas a partir da observação das ruas chilenas das cidades de Santiago e Valparaiso, no mesmo ano, de um movimento emblemático para a América Latina e as marcas (literalmente) deixadas nas ruas com referência à luta antineoliberal, captadas por meio de fotografias. Vale a ressalva que não se trata 
de um trabalho de análise do discurso ou específico sobre pichações ou mensagens e sim de uma leitura sobre as manifestações populares, que encontra em frases registradas nas ruas, sinais explícitos da abordagem que se quer realizar. Assim, tanto o material empírico de pesquisa, quanto a temática em si, fazem-se em um movimento dialético constante, do particular ao universal, do local ao latino-americano (que nesse caso é mundial também) tomando referências também locais para a compreensão de uma questão hegemônica como o domínio capitalista neoliberal e as suas ações contra hegemônicas praticadas pelas ruas da América Latina.

\section{Resultados e discussões}

4.1 Lutas e Esperanças em movimento: a experiência chilena

As manifestações nas ruas chilenas são as mais emblemáticas em todos os aspectos. Não somente por ser o foco de delimitação do presente artigo. Pode-se afirmar que se trata da mais consistente irrupção popular, não somente do ano citado, mas de toda a história recente da América Latina, no que tange a intensidade dos fenômenos de protestos. Isso se expressa na produção acadêmica sobre os fatos e é, sem dúvida, o conjunto de manifestações que detém o maior número de registros científicos e literários. Em termos de livros, frente às datas próximas, as manifestações chilenas já contam com considerável produção (Araújo et al. 2019; Folchi, 2019; Romo, 2020 e Vergara, 2021), sem contar inúmeros artigos publicados em diversos periódicos, no Chile e fora dele.

Ainda que os movimentos chilenos sejam multifatoriais e se transformem em seu processo de desenvolvimento, é possível localizar alguns elementos comuns provenientes do conjunto de análise e fincar uma materialidade objetiva oriunda da intensificação do modelo neoliberal do país. O estopim das manifestações envolve os estudantes, movimento ativo no país. Em resposta ao reajuste das passagens de metrô na capital chilena, os estudantes iniciaram, em outubro de 2019, uma ação de rechaço, inicialmente nas estações, que depois ganharam as ruas e mais contornos. As condições de precarização da vida cotidiana, precariedade dos serviços, modelo previdenciário em decadência foi ampliando as demandas e o conjunto dos sujeitos em protesto nas ruas. A repressão que gerou mortes também foi um fator considerável para o aumento crescente no movimento que levou milhões de chilenos às ruas de diversas cidades do país. A constituição vigente do país, remanescente dos tempos "áureos" de ditadura política e plenitude do modelo neoliberal foi se tornando centro dos questionamentos.

O contexto amplo, do conjunto de precariedades, é responsável por uma ação coletiva e multicolorida em torno dos movimentos que a compõe. Em uma obra voltada para da "revolta" chilena, o organizador indica tal multiplicidade e também o fator de igualdade.

La articulación hegemónica entre el movimiento obrero que com todas sus crisis no deja nunca de reinventarse, la audacia de la juventud, el sello revolucionario del feminismo, la conciencia por la salvación de la tierra y un sin número de luchas y sujetos que han irrumpido en el Chile actual (...) han sido los protagonistas del surgir de la revuelta y 
apostamos también que protagonicen el epílogo de la muerte del neoliberalismo en Chile (VERGARA, 2021, p.41).

Ressaltamos a unidade destacada em torno da classe trabalhadora, bem como os sujeitos coletivos elencados: a juventude em primeiro plano, com a força do movimento estudantil, as mulheres e o movimento feminista, os camponeses e demais conjuntos e sujeitos. Em uma palavra, trata-se de um movimento plural, com toda amplitude já destacada, mas sempre com ponto de unificação.

O contexto mais detalhado pode ser consultado nas obras já indicadas anteriormente. Ressalto que nosso interesse aqui é evidenciar como as ruas se manifestam contra o neoliberalismo. Portanto, vamos fazê-lo a partir das imagens, como já fora indicado. Sobre a gênese do processo, já localizamos a datação na década de 1970, com apoio de Harvey (2018), a origem da adoção das políticas neoliberais no Chile. Esse fato não é somente um precedente histórico. A adoção de tal modelo ganha status de referência para as políticas em outros estados nacionais, como afirmam os autores ao analisar o fenômeno de 2019: "en Chile un modelo neoliberal que fue considerado por muchos centros y gobiernos de derecha como un "laboratorio" y/o un "ejemplo" de las políticas que debían seguir los países" (STECHER; SISTO, 2019, p. 41-42).

Em reação à tal tradição, a premissa que sustenta a resistência e virou slogan nos muros chilenos é: "El neoliberalismo nace y muere en Chile". É uma frase que se repete nas ruas das diferentes cidades chilenas e está cheia de significados que, de forma certeira, captura a organização estrutural da realidade chilena (e que poderia ser ampliada para os demais países da América Latina), enquanto nascedouro/laboratório das políticas neoliberais da América Latina, mas também do modo como - no longo prazo - tal "laboratório de políticas neoliberais" tornou-se um cenário da resistência que traz à tona o processo de convulsão social resultante de tal neoliberalismo. Nasce/morre são, aparentemente, a contradição fundante da existência humana, mas ao metaforizar um processo econômico são ressignificados: a luta pela morte do sistema neoliberal é a morte da miserabilização da população, das práticas que empurram a população envelhecida para a rua e para a fome. Paradoxalmente a morte é o nascimento de um conjunto de práticas relacionadas aos protestos, à resistência, que não cobram o governo chileno apenas, mas cobram o capital e a forma como ele articula seus processos para manter a lógica mercantil funcionando. 


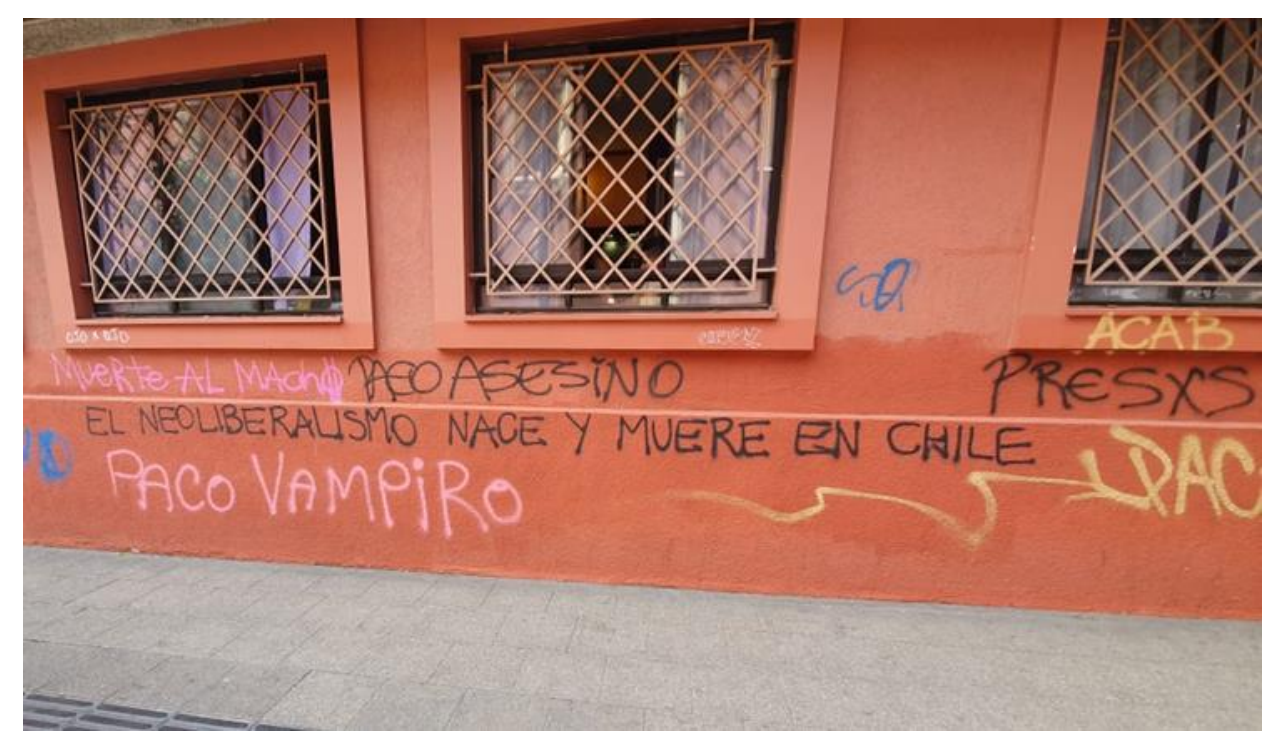

Fonte: Arquivo Pessoal, 2019.

A consciência histórica das ações nas manifestações está inserida em uma compreensão do paradigma integrado da organização social e do próprio modo de produção vigente. É o que se encontra expressado na frase: "Si paramos el país, el sistema caerá". É possível constatar a prática da afirmação acima nas ruas, na vontade com a qual os manifestantes se colocam e buscam ações, que parecem difusas, mas não são. De uma maneira estruturada ainda que informalmente, são orgânicas em torno de um objetivo robustamente envolto de intelectualidade e consciência política, histórica, econômica e sociológica. $E$, no movimento dialético, a origem de tais percepções se dá pela materialidade oriunda da prática de políticas neoliberais implantadas ao longo dos anos no país. Assim, "(...) las tensiones subjetivas de los sujetos neoliberales son el reflejo de las tensiones estructurales del sistema (...) (SISTO; FARDELLA, 2019, p. 263).

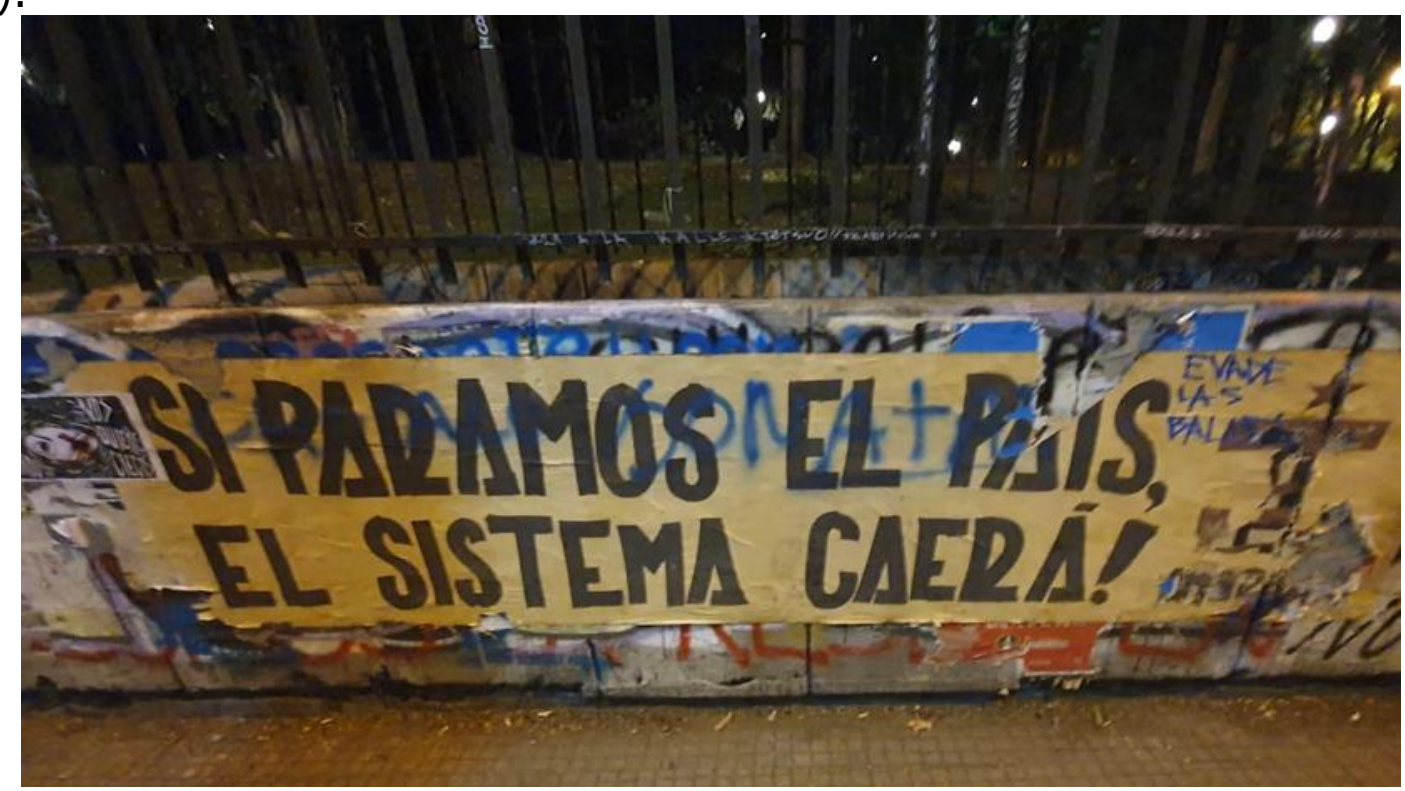

Fonte: Arquivo Pessoal, 2019. 
No contexto dessa crítica, há uma forte contraposição à sociedade de mercado, à mercantilização da vida, ou seja, uma crítica ao sistema do capital. É expressa de forma simples, mas como já fora dito, provida de muito conteúdo. A máxima "Chile no se vende" se repete ao longo das ruas e é uma crítica do movimento antissistêmico, orgânico e coerente com análises gerais, que veem na lógica capitalista barreiras intransponíveis para a emancipação. É uma crítica contundente contra a mercantilização de produtos ou bens sociais como a educação, saúde e, no caso chileno, principalmente previdência, que também são reivindicados nas ruas pelos manifestantes, no Chile e em outros países da América Latina.

A análise também vai para a organização estatal interna, ou seja, dos próprios governos, como se pode ver na expressão: "No + gobierno de mercado." Cabe uma ressalva também para análise popular que vai além do movimento oposição situacional: o governo de mercado está inserido também na proposta de governos alinhados à esquerda, como o da presidente Michelle Bachelet, o que denota a sabedoria do movimento atual, que não se restringe ao movimento político institucional e sabe bem da raiz dos males imediatos e estruturais. Em síntese, há um reconhecimento da governança para o mercado imposta no Chile como projeto, que é intensificada em governos alinhados imediatamente à tal perspectiva, como é o governo de Sabastian Piñera, contestado nas ruas em 2019.

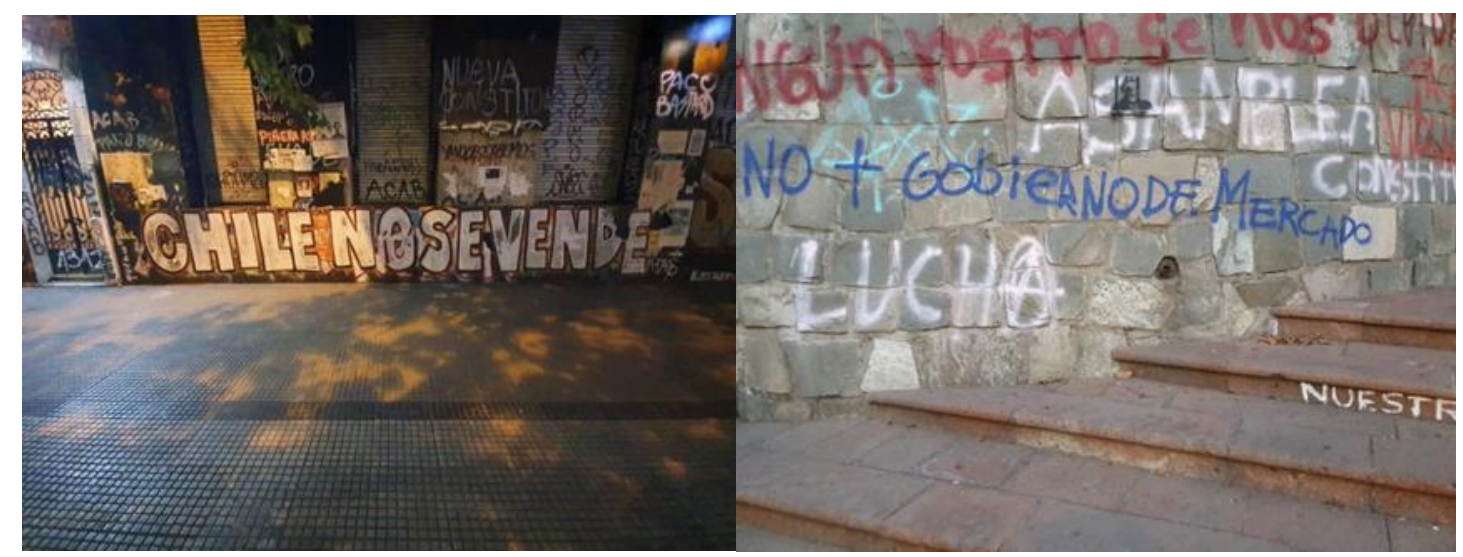

Fonte: Arquivo Pessoal, 2019.

Os dizeres acima ilustram os estudos que vêm sendo demonstrados pelos intelectuais quando se debruçam sobre a origem dos protestos de 2019. José Manuel Zavala C, professor da Universidade do Chile, ao ressaltar o papel dos povos originários nas manifestações, faz uma consideração que evidencia e respalda as inscrições das ruas e, de forma mais emblemática, denuncia o caráter "doutrinador" que o mercado tem exercido na sociedade chilena:

Pero finalmente el globo explotó y la paciencia se agotó, aflorando las contradicciones internas del modelo y las verdades que ahora todos reconocen, y antes muchos callaron. $Y$ es que en el ADN del modelo económico imperante está la creación de la desigualdade y de la injusticia. En efecto, al convertir al mercado en religión y en razón técnica inapelable de todas las interacciones económico-sociales y de las relaciones de los humanos con la naturaleza éstas se han vuelto completamente 
dependente de mercados internacionales que orientan al sistema productivo del país (ZAVALA, 2019, p. 94-95).

O caráter dialético das manifestações é uma característica pertinente. Assim como a citação acima demonstra, há um movimento ideológico concreto, que seduz para o mercado, contraposto às condições precárias que esse processo oferece à população e a explosão popular de revolta frente a esse quadro. No entanto, esse movimento não é somente o resultado da precarização. As ruas evidenciam também, postulando a superação do momento atual, o fim do neoliberalismo, o que contém uma percepção científica, apurada e sistêmica, que vai além da pura e simples reação.

É necessário reconhecer nos protestos presentes nas ruas hoje, tomando como base os escritos chilenos, mas olhando também para os demais países citados e, principalmente, aos protestos que ainda estão por vir, o objetivo que é claro: "Muerte al neoliberal" (escrito em um banco), que pode parecer drástico ou até pessoalizado (para quem não fizer a leitura elíptica de "sistema" que o enunciado carrega), mas é um objetivo analítico necessário para a construção de um modelo societário no qual não caibam desigualdades e as mazelas delas oriundas. Essa espécie de "denúncia" do sistema, somado à consciência histórica e às esperanças que vêm das ruas, que identificam nas lutas uma assertiva ousada: "Seremos la tumba del neoliberalismo".

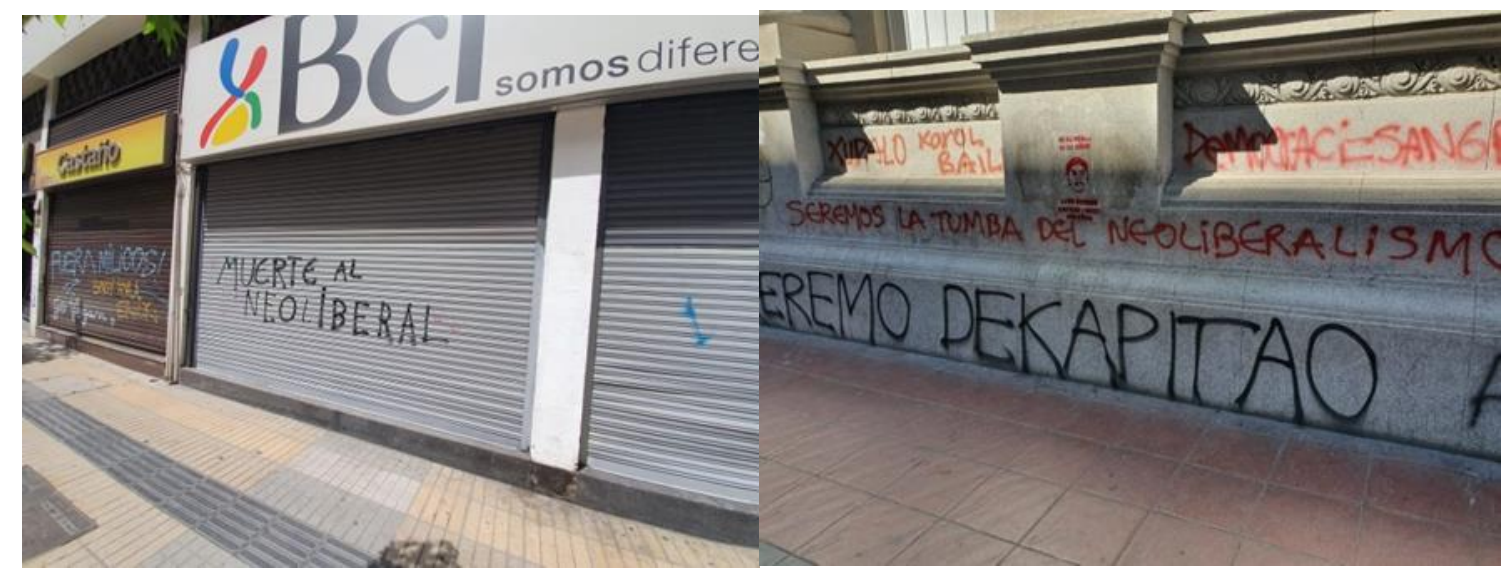

Fonte: Arquivo Pessoal, 2019.

Finalizamos as reflexões em torno dos escritos nas ruas chilenas, intencionalmente com essa afirmação de que os manifestantes postulam "enterrar" o neoliberalismo do país, pois, a intenção do artigo, além de demostrar a vinculação das demandas que estão nas ruas com o sistema neoliberal, é também destacar o enfrentamento político que está sendo feito ao sistema. Não é fato, como pleiteia o próprio neoliberalismo, o chamado "fim da história". As ruas têm evidenciado isso com suas manifestações pelo mundo todo e principalmente na América Latina. As evidências que ilustram o debate deste texto expressas, por meio das fotografias das ruas chilenas, mostram que há uma coerência política, histórica, social e, também, epistemológica das manifestações com o objetivo antissistêmico.

\section{Considerações finais}


O presente artigo foi iniciado com conceituações amplas sobre os movimentos antissistêmicos justamente para evidenciar que o momento abordado - o ano de 2019 - seja na variedade dos países latino-americanos, seja no caso chileno, não são ações de massas espontâneas, ou simples revoltas às condições de vida atuais. O que as ruas manifestaram nos casos abordados está inserido em um movimento mais amplo, com antecedentes históricos e também com um grau de intencionalidade e pontos de convergências com outros movimentos sociais.

Ainda que o texto não tenha se detido devidamente ao conjunto das manifestações ocorridas na maioria dos países latino-americanos no ano de 2019, as referências e casos expostos evidenciam o registro de manifestações de rua em um contingente significativo dos países da região. Destacamos que cada caso tem uma natureza, particularidade e condicionantes próprios, porém podem ser indicadas simetrias. Ao se manifestar sobre as similitudes dos protestos chilenos, Azun Candina Polomer consegue sintetizar o que ocorre nos processos da região como um todo, com bastante precisão:

La mayoría de esas movilizaciones fueron pluriclasistas, y apesar de su heterogeneidad, todas ellas compartieron una crítica profunda al modelo económico y político neoliberal y al Estado subsidiario, y demandaron políticas solidarias y redistributivas y una mayor participación en la política y sus decisiones. (POLOMER 2019, p. 56)

O caso das manifestações no Chile foi bastante emblemático. Foram as manifestações mais intensas, tanto na extensão dos protestos, que adentraram os anos posteriores, como na quantidade de pessoas que tomaram as ruas das cidades pelo país. Igualmente histórica é a relação desse Estado nacional com as políticas neoliberais. De longa data, o povo chileno sofre as consequências do Estado mínimo nos diversos setores das políticas sociais. Esse é o motivo pela escolha de tal espaço para realizar o trabalho mais empírico da pesquisa, registrando as manifestações permanentes das ruas por meio dos escritos dos manifestantes.

Entre os amplos movimentos antissistêmicos, fizemos referência à especialização do movimento antineoliberal. Porém, como indicado no desenvolvimento do artigo, compreendemos que tais movimentos, no período histórico atual, cumprem em alguma medida um enfrentamento ao modelo neoliberal. Assim, a partir das ruas chilenas, é possível afirmar que as ruas da América Latina, em 2019, manifestaram-se contra o neoliberalismo entre suas pautas.

A força do sistema capitalista e em sua versão neoliberal é esmagadora. Infelizmente, o saldo das ações estatais, na região estudada e pelo mundo afora, não são favoráveis à classe trabalhadora. Supressão de direitos, altos índices de concentração econômica, consequente aumento da desigualdade são resultados da intensificação da exploração e consolidação do sistema. Um indicativo importante de tal fato pode ser o ascenso dos governos ultraconservadores pelo mundo que, no que tange ao mercado, são alinhados às premissas neoliberais, em sua essência. 
Porém, como o artigo se propôs a evidenciar a resistência das ruas acerca de tais fenômenos, concluímos que as ações citadas são essenciais para frear o avanço sistêmico. E o povo chileno mostrou que é possível avançar. Como resultado das lutas das ruas, foi "arrancado" do Estado a realização de um referendo nacional que aprovou por larga vantagem uma assembleia nacional constituinte que irá construir uma nova constituição para o Chile e superar a atual, construída sob a ditadura militar. Ou seja, a lição das ruas é a esperança.

\section{REFERÊNCIAS}

ABITBOL, Pablo. ¿Por qué protestan en Colombia? Movilizaciones, reclamos de paz y crisis de la derecha. Centre tricontinental. https://www.cetri.be, 2021. Centre tricontinental. Disponível em: <https://www.cetri.be/Por-que-protestan-en-Colombia>. Acesso em: 25 jan. 2021.

AGUILAR-FORERO, Nicolás. Las cuatro co de la acción colectiva juvenil: el caso del paro nacional de Colombia. Analisis Politico. v. 32, n. 98, p. 26-43, 2020. Universidad Nacional de Colombia. Disponível em:

<https://revistas.unal.edu.co/index.php/anpol/article/view/89408>. Acesso em: 24 jan. 2021.

ARAUJO, Kathya (ed.). Hilos tensados. Para leer el octubre chileno. Santiago: Editorial USACH, 2019.

ARIAS, Santine Ribeiro. O perfil da classe média do movimento altermundialista: o caso ATTAC, 2003. 176f. Tese (Doutorado em Ciência Política) - Instituto de Filosofia e Ciências Humanas, Universidade Estadual de Campinas, Campinas, 2003.

ARRIGHI, Giovanni; HOPKINS, Terence Kilbourne; WALLERSTEIN, Immanuel. Antisystemic Movements. London, New York: Verso, 1989.

BORDA, Sandra. Parar para Avanzar. Crónica del Movimiento Estudiantil durante el histórico paro nacional de 2019. Bogotá: Bogotá: Editorial Planeta, 2020.

BRINGEL, Breno; MUÑOZ, Enara Echart. Dez anos de Seattle, o movimento antiglobalização e a ação coletiva transnacional. Ciências Sociais Unisinos. v. 46 , n. 1 , p. $28-36,2010$.

BUBEN, Radek; KOUBA, Karel. Nicaragua in 2019: The Surprising Resilience of Authoritarianism in the Aftermath of Regime Crisis. Revista de Ciência Política v. 40, n. 2, p. 431-455, 2020. 
CARVALHO, Giane Carmem Alves de. Os movimentos anti-sistêmicos: conjuntura de lutas ou impasses políticos ideológicos? Mediações - Revista de Ciências Sociais. v. 13, n. 1/2, p. 214-230, 2008.

CERVA CERNA, Daniela. La protesta feminista en México. La misoginia en el discurso institucional y en las redes sociodigitales. Revista Mexicana de Ciencias Políticas y Sociales. v. 65, n. 240, 2020.

ESQUIVEL DOMÍNGUEZ, Daniela Carolina. Construcción de la protesta feminista en hashtags: aproximaciones desde el análisis de redes sociales. Comunicación y médios. v. 28, n. 40, p. 184-198, 2019.

FOLCHI, Mauricio. Chile despertó. Lecturas desde la Historia del estallido social de octubre. Santiago: Universidad de Chile, 2019.

GIOVANNI, Julia Ruiz Di. Cadernos do outro mundo: o Fórum Social Mundial em Porto Alegre. 2013. 158f. Tese. (Doutorado em Antropologia Social) Universidade de São Paulo, São Paulo, 2013.

GOHN, Maria da Glória. Participação e democracia no Brasil: da década de 1960 aos impactos pós-junho de 2013. Petrópolis: Editora Vozes, 2019.

HOBSBAWM, Eric John. Rebeldes primitivos: estudos sobre formas arcaicas de movimentos sociais nos séculos XIX e XX. Rio de Janeiro: Zahar Editores, 1970.

LÖWY, Michel. Negatividade e utopia do movimento altermundialista. Lutas Sociais. n. 19/20, 2008. p.32-38.

POLOMER, Azun Candina. La clase media que no era: ira social y pobreza en Chile. In: FOLCHI, Mauricio (org). Chile despertó. Lecturas desde la Historia del estallido social de octubre. Santiago: Universidad de Chile, 2019.

RETTBERG, Angelika. Colombia in 2019: The Paradox of Plenty. Revista de Ciência Política. v. 40, n. 2, p. 235-258, 2020

RODRÍGUEZ, Cecilia Graciela; TULE, Luis. Gonzalez. Honduras 2019: persistente inestabilidad económica y social y debilidad institucional. Revista de ciencia política (Santiago). v. 40, 2020.

ROJAS, Carlos Antonio Aguirre. O que são os movimentos antissistêmicos? Revista Eletrônica História em Reflexão. v. 7, n. 13, 2013.

ROMO, Magdalena Merbilháa. Nuestro Octubre Rojo. Orígenes De Un Estallido Social. Santiago: El Libero, 2020. 
SANTOS, Boaventura de Souza. O fórum social mundial: manual de uso. São Paulo: Cortez, 2005.

SEOANE, Jose; TADDEI, Emilio; De Seattle a Porto Alegre - Passado, presente e futuro do movimento antimundialização neoliberal. In: SEOANE, Jose; TADDEI, Emilio. (Orgs.); Resistências mundiais: de Seattle a Porto Alegre. Petrópolis: Vozes, 2001.

SISTO, Vicente; FARDELLA, Carla. Del yo al nosotros: el emplazamiento colectivo a las subjetividades neoliberales. In: ARAUJO, Khatia. (Org.); Hilos tensados. Para leer el octubre chileno. Santiago: Editorial USACH Santiago, 2019. p.243-270

STECHER, Antonio; SISTO, Vicente. Trabajo y precarización laboral en el Chile neoliberal. Apuntes para comprender el estallido social de octubre 2019. In: ARAUJO, Khatia. (Org.); Hilos tensados: Para leer el octubre chileno. Santiago: USACH, 2019. p.37-82.

TALANQUER, Mariano Sanchez. Personalistic politics and neoliberalism from the left. Revista de Ciência Política. v. 40, n. 2, 2020. p. 401-430.

VERGARA, Marco Álvarez. (coord.) La revuelta chilena. Estrategia, izquierdas y movimientos sociales. Santiago: Pehuyén Editores, 2021.

VISENTAINER, Kátia. América Latina: palco de protestos em 2019. Disponível em: https://medium.com/@padbrazil/américa-latina-palco-de-protestos-em2019-8029b62a6602. Acesso em: 2 fev. 2021.

WALLERSTEIN, Immanuel. O que significa hoje ser um movimento antisistêmico. LEHER, Roberto; SETÚBAL, Mariana. (Orgs.). Pensamento crítico e movimentos sociais. São Paulo: Cortez, 2005. p.263-276.

ZAMORANO, Juan. AP Explica: Protestas ante reforma constitucional en Panamá. AP News, 2019. Ciudad del Panamá. Disponível em: https://apnews.com/article/1f8b6a20e290452cb67e561139c282b2. Acesso em: 8 fev. 2021.

ZAVALA, José Manuel. Los pueblos originarios y un nuevo orden político para Chile. In: FOLCHI, Maurcio. (Org.); Chile Despertó. Lecturas desde la Historia del estallido social de octubre. Santiago: Universidad de Chile, 2019. p. 93-98. 